\title{
An integrated program with home blood-pressure monitoring and village health volunteers for treating poorly controlled hypertension at the primary care level in an urban community of Thailand
}

This article was published in the following Dove Press journal: Integrated Blood Pressure Control

\author{
Sawitree Visanuyothin ${ }^{1,2}$ \\ Samlee Plianbangchang' \\ Ratana Somrongthong' \\ 'College of Public Health Sciences, \\ Chulalongkorn University, \\ Bangkok, Thailand; ${ }^{2}$ Social Medicine \\ Department, Maharat Nakhon \\ Ratchasima Hospital, Nakhon \\ Ratchasima, Thailand
}

\begin{abstract}
Purpose: Hypertension (HT) is accountable for death in half of the patients suffering from heart disease and stroke. Many treatment strategies have been used, but little research exists on an integrated program with home blood pressure monitoring (HBPM) and village health volunteers (VHVs) in an urban area of Thailand. The present study aims to determine the effectiveness of the integrated program, HBPM, and VHVs in supporting the target population.
\end{abstract}

Patients and methods: This quasi-experiment was conducted from July to November 2017. Patients with poorly controlled HT were randomly selected from each of the two primary care units in Nakhon Ratchasima, Thailand. The participants were separated into an experiment $(n=63)$ and control group $(n=65)$. The experiment group participated in the integrated program, which was based on the 20-item Health Literate Care Model. A valid and reliable questionnaire was used to collect data from participant interviews. Blood-pressure monitoring was used to measure systolic home blood pressure and diastolic home blood pressure. Descriptive statistics, chi-squared tests, Fisher's exact test, the independent $t$-test, and the Wilcoxon-Mann-Whitney test were used to compare the baseline data. Multiple logistic regression was used to compare the differences between the mean changes in the outcomes.

Results: At the end of the 3-month follow-up appointment, significant statistical changes were found. Systolic home blood pressure, diastolic home blood pressure, and body mass index changed $-4.61(95 \% \mathrm{CI}-8.32,-0.90) \mathrm{mmHg}(P$-value $=0.015),-3.5(95 \% \mathrm{CI}-5.31,-1.72)$ $\mathrm{mmHg}(P$-value $<0.001)$, and $-0.86(95 \% \mathrm{CI}-1.29,-042)(P$-value $<0.001)$ respectively. Participant scores in lifestyle and management knowledge, and self-management behaviors significantly increased by $0.76(95 \%$ CI $0.15-1.38)$ point $(P$-value $=0.016)$ and $0.15(95 \% \mathrm{CI}$ $0.06,0.24)$ point $(P$-value $=0.001)$, respectively.

Conclusion: The integrated program, HBPM, and VHVs were effective in decreasing blood pressure and body mass index, and increasing knowledge and self-management behaviors among urban patients with poorly controlled HT.

Keywords: self-management behaviors, lifestyle and management knowledge, health literacy of chronic diseases, adherence of hypertension patients

\section{Introduction}

In 2008, adults aged $\geq 25$ years who had been diagnosed with hypertension (HT) or high/raised blood pressure (BP) comprised around $40 \%$ of the global population. \footnotetext{
College of Public Health Sciences, building 3 (I0th-I I th) Chulalongkorn soi 62, Bangkok 10330, Thailand Tel +66 8I 8I73530 Email samleep40@gmail.com
} 
The prevalence of undiagnosed, untreated, and uncontrolled HT is often higher in low- and middle-income countries. HT prevalence increases due to population growth, ageing, and behavioral risk factors. ${ }^{1} \mathrm{HT}$ is a major cause of cardiovascular disease (CVD), which can result in coronary heart disease, congestive heart failure, stroke, renal failure (RF), and peripheral arterial disease. ${ }^{2}$ Going by global death statistics, $\geq 45 \%$ of HT cases account for death from heart disease and $51 \%$ of HT cases account for death from stroke. ${ }^{1}$ The estimated mortality rates from Ischemic Heart Disease (IHD), stroke, and HT, as well as the disability-adjusted life year, were higher in 2012 than in $2000 .^{3}$ In addition, the treatment of long-term conditions resulted in catastrophic health expenditures. ${ }^{1}$ Health and literacy are important assets for a patient's livelihood, and patients with low health literacy had poorer health status and higher mortality rates than average. ${ }^{4-7}$ As the risk of CVD doubles with each incremental, $20 / 10-\mathrm{mmHg}$ increase in $\mathrm{BP},{ }^{8}$ poorly controlled HT presents a challenge. This is especially true of systolic HT, which is the main etiology in patients with uncontrolled HT. ${ }^{9}$

Many strategies have been used to treat poorly controlled HT, which can be categorized into: 1) self-monitoring, 2) educational interventions directed toward the patient, 3) educational interventions directed toward the health professional, 4) health-professional-led care (eg, nurse or pharmacist), 5) organizational interventions aiming to improve the delivery of care, and 6) appointment reminder systems. ${ }^{10}$ In terms of health-literacy interventions, there were contradictions in previous studies. Hypertensive and coronary patients in urban primary care units (PCUs) who had low health literacy were 1.74 times more likely to have uncontrolled BP than those who scored higher. ${ }^{11}$ In contrast, a cross-sectional study on primary care patients revealed a 3-point increase in Brief Health Literacy Screen (BHLS) scores, which correlated with a $0.74 \mathrm{mmHg}$ increase in systolic BP (sBP) and 0.30 increase in diastolic BP (dBP). ${ }^{12}$ The Chronic Care Model (CCM) has been widely used to improve outcomes among patients with chronic diseases; however, the CCM was considered insufficient for improving patient engagement and there was a need for healthcare providers to approach all patients with the assumption that they did not understand the medical information supplied to them. Therefore, the Health Literate Care Model (HLCM) was built by the Agency for Healthcare Research and Quality (AHRQ) in 2010, including the AHRQ Health Literacy Universal Precautions Toolkit. This model represents a comprehensive, synergistic, proactive, and practical framework that can be adapted to all patients' health-literacy challenges. The HLCM can also reduce duplication and inefficiency, and improve patients' understandings of and engagements in their own health care. ${ }^{13}$ Thus, in the present study, the HLCM was chosen to design the intervention for controlling BP.

In developed countries, home blood pressure monitoring (HBPM) has been used to diagnose and control HT for many decades. The superiority of HBPM, compared to clinical measurements, in uncontrolled HT diagnosis, antihypertensive drug assessment, compliance improvement, and HT control have been previously defined. HBPM has been proven to effectively lower BP. Medication compliance was improved by HBPM, especially when combined with other adherence strategies. ${ }^{14}$ Studies have shown that community health workers (CHWs) also play a role in patient BP reduction. ${ }^{15,16}$ Trained $\mathrm{CHWs}$ ask their patients to consider any changes they want to make regarding physician interactions and help patients identify sources of support for their new behaviors and strategies to overcome any anticipated problems. ${ }^{15} \mathrm{CHWs}$ are also trained to coach patients and family members in HBPM, drug adherence, and lifestyle modification. ${ }^{16}$ However, few reviews exist of the HLCM-based integrated program with HBPM and village health volunteers (VHVs) for treating patients with poorly controlled HT in urban areas. The present study aims to determine the effectiveness of the integrated program in treating the target population.

\section{Materials and methods \\ Study design}

This quasi-experimental study was conducted from July to November 2017. All stakeholders, including the participants and VHVs, were not blinded to the intervention assignment.

\section{Study area}

Thailand is subdivided into 76 provinces. The Ministry of Public Health in Thailand operates health care services through 28 regional hospitals, 88 general hospitals, 780 community hospitals, 295 municipality health centers, and 9777 PCUs. ${ }^{17}$ Regional/general/community hospitals coordinate with district health offices (DHOs) to administrate PCUs. Mostly the general hospitals and community hospitals administrate PCUs in the inner city but DHOs manage remote PCUs. PCUs provide health promotion, disease prevention, basic medical care, chronic disease and palliative care management, and rehabilitation. PCUs of regional/general/community hospitals have a higher chance to provide services by doctors in the urban area than PCUs under DHO. Nakhon Ratchasima province is in the northeast region of Thailand. The province has the largest 
area and ranks second in nationwide population. Muang District is the center of the province, which hosts 46 PCUs that served a population of 469,682 in 2014. To Avoid not enough sample and loss follow-up problems, selected PCU must not be located in the middle point of an urban area where many schools, malls, and official places including hospitals are located Two PCUs were selected: one that hosted the experiment, which had the high prevalence of HT and high population, and one that would serve as a control. The control and experiment PCUs were similar in terms of their health service systems and staff.

\section{Study population and sample}

The target population included patients with poorly controlled HT who were registered and resided in the urban areas of Nakhon Ratchasima, Thailand. The last three BP measurements for each patient were retrieved from the HOSXp database of their corresponding PCU. The average BP across all patients was calculated, and then the study participants were recruited from those who had an average BP that was $>140 / 90 \mathrm{mmHg}$ and who met the inclusion criteria. Research assistants grouped those name of patients by community and family folder, and then the names were sent to family nurses for screening according to inclusion and exclusion criteria. When VHVs got the names of patients who met the inclusion criteria, they knocked on the patients' door to ascertain their willing to join this study. The participants were eligible for this study if they were aged 30-70 years, were registered patients, were diagnosed with essential HT and had an average BP (last three visits) $>140 / 90 \mathrm{mmHg}$, had lived in the study area for at least 1 year, were willing to participate in the research, and could communicate and write effectively in Thai. Participants were ineligible if they met any of the following exclusion criteria: BP of 200/100 $\mathrm{mmHg}$; diagnosed with postural hypotension; diagnosed with a terminal disease, such as CVD, cerebrovascular accident, RF, or cancer; psychiatric hospitalization within the past 2 years; pregnant or breastfeeding; planning to leave the study area prior to the anticipated end of participation; currently taking medication for the treatment of psychosis or manic depression; or took a weight-loss medication in the 3 months prior to the first screening visit.

The sample size was calculated using the following formula:

$$
n=\frac{2[z \alpha+z \beta]^{2} \sigma^{2}}{\Delta^{2}},
$$

where $\sigma$ is the standard deviation of $\operatorname{sBP}(11.2)$,

$\beta$ is 0.2 (power 80 ), and

$\Delta$ is the effect size of the mean sBP change between case and control (5.5).

After adding an attrition rate of $30 \%$, the calculated sample size for each group was found to be 67 ; thus, the total number of participants required was 134 . The participants were coded by number in both PCUs and were separately and randomly assigned to the experiment or control group until each group had 67 participants. The participants were subsequently contacted, received an explanation of the study, and asked whether they wanted to join the program. If a participant decided to join, an appointment date was set between the participant and researchers to discuss the program in greater detail and to collect the participant's informed consent. If a participant decided not to join, the researchers drew a replacement. The study enrolled 63 patients with poorly controlled HT in the experiment group and 65 patients in the control group. Due to dropout, there were 62 in the experiment group and 60 in the control group, who completed the study process.

\section{Research instruments}

Two measurement tools were employed in this study, which are as follows: 1) questionnaires, 2) BP monitoring. The adjusted questionnaire comprised the following five sections: 1) demographic data, 2) lifestyle and management knowledge, ${ }^{18} 3$ ) health literacy (adapted from a selfadministered questionnaire on Thai people's health literacy level constructed by the Health Systems Research Institute [HSRI] of Thailand), ${ }^{19} 4$ ) self-management behaviors, ${ }^{20}$ and 5) adherence. ${ }^{21,22}$ The instruments of data collection in this study are as follows.

\section{Questionnaires}

A questionnaire was used to collect data via face-to-face interviews, which was performed by research assistants. The questions were originally composed in English and later translated into Thai, except for questions in Section 3 , which were already in the Thai language. The questionnaires were sent to three experts for improvements based on the index of item objective congruence (IOC); the overall IOC was 0.8 , and the IOC for Sections $1,2,4$, and 5 were $0.8,0.8,0.9$, and 0.7 , respectively. The questionnaires were pretested on 30 patients with poorly controlled HT in a nearby, contextually similar PCU. There were 74 questions, including: 1) 16 questions on demographic characteristics, 2) 10 questions on lifestyle and management knowledge ( 9 
true/false questions and 1 multiple choice; KR-20=0.607), 3) 20 questions on health literacy, which included a fourpoint Likert scale for 7 questions on literacy and potential literacy and a 10-point Likert scale for 13 questions on self-care of chronic diseases (Cronbach's $\alpha$ : 0.960 for literacy and potential literacy, 0.861 for self-care of chronic diseases), 4) 22 questions on self-management behaviors with a 3-point Likert scale (Cronbach's $\alpha$ : 0.881), and 5) 7 questions on drug and appointment adherence (Cronbach's $\alpha: 0.968)$.

\section{Blood-pressure monitoring}

The Tele-Health Assisted System was provided to each participant to measure BP at home. The URIGHT TD-3128 blood-pressure monitoring system (ESH 2010 approval), with support from Connect Diagnostics Co. Ltd, was provided only to participants in the experiment group, who received training in its use.

\section{The integrated program}

The integrated program was based on the HLCM and includes HBPM and VHV support to ensure quality of care and improve BP control among patients with poorly controlled HT. Intervention mapping ${ }^{23}$ was applied during the development of this program and the program was divided into two phases.

\section{Usual care}

In the control PCU, neither the $20 \mathrm{VHVs}$ nor participants were trained to perform the intervention, except for BP measurements by VHVs at 7 days of baseline and 3 months. In addition, organizational improvements, based on the HLCM and stakeholder involvement, were not offered to the control PCU. The participants did not receive the 2-day workshop on self-management and the HBPM tool (TD-3128). The control participants received home visits or calls from the VHVs for advice as usual, which is not a weekly approach.

\section{Outcomes}

The primary outcomes included the differences between experiment and control groups in mean systolic home blood pressure (sHBP) and diastolic home blood pressure (dHBP) from baseline to the end of the program. The secondary outcomes included body mass index (BMI), waist circumference (WC), lifestyle and management knowledge, health literacy, self-management behaviors, and drug and appointment adherence.

\section{First phase ( 2 months)}

\section{Team, program, and tools creation}

During the first phase of the study, the researchers conducted a literature review. Four group discussions were held with all stakeholders to define the strengths, resources, and potential of the experiment PCU and the community they are responsible for, including problems based on the 20 -item HLCM and improvements to HT care. The stakeholders involved in this process included 2 hypertensive patients, 25 VHVs, 7 family nurses, 3 public health personnel, 1 pharmacist, and 1 family doctor. The first group discussion included all stakeholders to define the strengths and problems. The second group discussion was held to develop the HT information system, which involved a multidisciplinary team and a computer technician. The third group discussion provided critique and improvements to the HT clinical practice guideline (CPG) of the Primary Care Cluster (PCC) and an HT picture book. The consultation hotline group was also set during this meeting. The fourth group discussion was conducted to create an appropriate workshop for selfmanagement. The first draft of the program was created from these discussions, and the second draft was presented to the community twice so that it could be appropriately revised. The final program was subsequently written and distributed to all stakeholders.

\section{Preparation for VHVs}

A team meeting was held involving all stakeholders. Two informal, collaborative teams were established. The first team was designated the "HT team" of the hotline group, which consisted of researchers, cardiologists, family doctors, family nurses, healthcare workers, and technicians from both the experiment and control PCUs. This team was responsible for running the overall program. The second team was a family care team from the experiment PCU, which cared for its patients while closely following the program plan. The VHVs established a hotline group, called "Love HT," to communicate, support, and manage the patients' problems with support from the VHVs, family nurses, and a family doctor. Research assistants and healthcare workers were trained to use the HBPM tool (TD-3128) and the URIGHT Telehealth software to collect, check, retrieve, and present the patients' data. Twenty-three VHVs from the experiment PCU received a refresher course on the risks, clinical diagnosis, treatment, and complications of HT. They were also trained to use the TD-3128 and ask patients three Thai-modified questions, as follows: 
1. What is your main problem in HT control?

2. What method do you use to solve your problem?

3. Why is this method important for controlling your HT?

Simple instructions were created for the experiment participants and the VHVs. Twenty VHVs from the control group were trained to use the TD-3128 only, without the Thaimodified questions. All VHVs and participants from both the experiment and control groups received a 7-day baseline and 3 months of HBPM schedule.

\section{Second phase (3 months)}

There were four main activities in this phase which were as follows:

1. Improve the primary care system by providing the HT CPG of the PCC to family doctors and nurses to aid in their decision-making regarding patient treatment.

2. Provide group-based health education on HBPM and self-monitoring during a 2-day workshop, including HBP measurement skills (see Table 1 for the workshop schedule).

Table I Two-day workshop schedule

\begin{tabular}{|c|c|c|}
\hline Day I sessions & Objectives & Activities and media \\
\hline $\begin{array}{l}\text { lce-breaking } \\
\text { activity: "Know } \\
\text { you, Know your } \\
\text { HT" }\end{array}$ & $\begin{array}{l}\text { - Enhance the relationship between patients } \\
\text { with poorly controlled HT and VHVs in } \\
\text { each community; } \\
\text { - Clarify the schedule of the whole program. }\end{array}$ & $\begin{array}{l}\text { - Assign patients into five groups by community. VHVs in charge of each } \\
\text { community acted as facilitators, along with the assigned research assistants. } \\
\text { - The patients introduce themselves then sing and dance together to the music } \\
\text { video "Know HT." } \\
\text { - Introduce the researchers, research assistants, family doctors, family nurses, } \\
\text { and VHVs. Also, review the program and its objectives. }\end{array}$ \\
\hline $\begin{array}{l}\text { Participatory } \\
\text { lecture: }\end{array}$ & $\begin{array}{l}\text { - Improve knowledge about HT, the } \\
\text { Dietary Approach to Stop Hypertension }\end{array}$ & $\begin{array}{l}\text { - Watch the videos on silent death and } \mathrm{HT} \text {, then play the question-and-answer } \\
\text { game. }\end{array}$ \\
\hline $\begin{array}{l}\text { "Preparing } \\
\text { for self- } \\
\text { management" }\end{array}$ & $\begin{array}{l}\text { program and exercises, stroke risk, } \\
\text { enhanced compliance with antihypertensive } \\
\text { medication, and self-management skills; } \\
\text { - Increase awareness of self-care to } \\
\text { control HT. }\end{array}$ & $\begin{array}{l}\text { - Provide the "Know HT" picture book with lyrics to the "Know HT" music } \\
\text { video to HT patients and their family members so they can read it and sing } \\
\text { the song at home (see the QR codes in Supplementary material). } \\
\text { - Watch the video on HT treatment, then play the question-and-answer game. }\end{array}$ \\
\hline $\begin{array}{l}\text { Group-based } \\
\text { learning }\end{array}$ & $\begin{array}{l}\text { - Foster understanding of blood pressure and } \\
\text { interpretation; } \\
\text { - Ensure the patients are able to measure } \\
\text { blood pressure and plan for self- } \\
\text { management. }\end{array}$ & $\begin{array}{l}\text { - Watch the video on HT definition and interpretation, then play the question- } \\
\text { and-answer game } \\
\text { - Each group takes their individual blood-pressure measurements with } \\
\text { guidance and instruction from the VHVs and research assistants. } \\
\text { - Clarify the blood-pressure measurement schedule together. }\end{array}$ \\
\hline Day 2 sessions & Objectives & Activities and media \\
\hline $\begin{array}{l}\text { Case-based and } \\
\text { group-based } \\
\text { learning about } \\
\text { living with HT }\end{array}$ & $\begin{array}{l}\text { - Increase patients' awareness of self- } \\
\text { regulation and management; } \\
\text { - Ensure the patients are able to evaluate } \\
\text { their self-management behaviors involved in } \\
\text { BP control. }\end{array}$ & $\begin{array}{l}\text { - Expert patients share their background as well as their self-observation, } \\
\text { self-regulation, and self-management techniques, then the patients play the } \\
\text { question-and-answer game. } \\
\text { - Each patient is paired with another patient, then the pairs share their } \\
\text { experiences of living with HT and how to observe and control HT. The pairs } \\
\text { then share the lessons they learned from their partner with their group. The } \\
\text { most valuable stories are selected to share with all the patients. } \\
\text { - The researchers summarize the patient's tips and tricks for self-managing HT. }\end{array}$ \\
\hline $\begin{array}{l}\text { Group-based } \\
\text { practices for } \\
\text { self-management }\end{array}$ & $\begin{array}{l}\text { Ensure the patients are able to practice } \\
\text { the } 3 \mathrm{E} 2 \mathrm{~S} \text { activities (3E: exercise, eating, } \\
\text { and emotion; } 2 \mathrm{~S} \text { : stop smoking and stop } \\
\text { drinking alcohol), take antihypertensive } \\
\text { medications regularly, take medications for } \\
\text { symptom management, and recognize acute } \\
\text { episodes. }\end{array}$ & $\begin{array}{l}\text { - Each group practices at each station for } 30 \text { minutes, then rotates to another } \\
\text { station until all five stations have been visited, as follows: } \\
\text { - Station I: Exercise for HT patients; } \\
\text { - Station 2: Eating a low-salt and low-fat diet; } \\
\text { - Station 3: Control emotions, stop smoking, and stop drinking alcohol; } \\
\text { - Station 4: Antihypertensive medications; } \\
\text { - Station 5: Emergencies and complications. }\end{array}$ \\
\hline $\begin{array}{l}\text { Group } \\
\text { discussion, goal } \\
\text { setting, and } \\
\text { resources for } \\
\text { achieving goals }\end{array}$ & $\begin{array}{l}\text { - Share problems; } \\
\text { - Set self-goals; } \\
\text { - Determine appropriate activities for self- } \\
\text { management and regulation. }\end{array}$ & $\begin{array}{l}\text { - Conduct a group discussion on "problem assessment and need identification" } \\
\text { to share goals for promoting self-management in controlling HT. } \\
\text { - Each patient writes in a personal notebook about their problems, self- } \\
\text { management, and self-regulation. } \\
\text { - Sing and dance to the "Know HT" music video, then receive encouragement } \\
\text { from the facilitators to engage in self-management. }\end{array}$ \\
\hline
\end{tabular}

Abbreviation: $\mathrm{HT}$, hypertension. 
3. Support patients with poorly controlled HT to use the TD-3128 to complete their daily HBPM twice in the morning and twice in the evening, following the recommended schedule.

4. Ensure the VHVs completed a home visit or call, provided weekly advice over 3 months, and asked each patient the three Thai-modified questions on HT control.

\section{Data collection}

A questionnaire was used to collect data at baseline and 3 months post intervention during face-to-face interviews by the trained research assistants, which took about 30 minutes each. The maximum score in lifestyle and management knowledge was 10; participants were categorized into low $(<6)$, moderate $(6-7)$, and high $(\geq 8) .{ }^{24}$ The maximum score in health literacy and potential literacy was 4 ; participants were divided into poor (1.1-2.0), moderate (2.1-3.0), and good (3.1-4 .0). The maximum score in self-care of chronic diseases was 10, but the HSRI did not categorize these scores. ${ }^{19}$ The maximum score for self-management behaviors was 3 ; participants were grouped into inadequate $(\leq 2.34)$ and adequate $(>2.34) .{ }^{25}$ The adherence level was calculated using the sum of points; participants were divided into three levels of adherence: high (8), medium (6-7), and low (score <6). ${ }^{21,22}$ After completing each interview, the researchers and assistants checked the data for completeness.

To collect the average BP at baseline and 3 months post intervention, the trained VHVs measured each participant's BP three times every morning for 7 consecutive days. The BP measurements were taken in the patients' homes when they were well rested, using the appropriate positioning and suitable BP cuff size. The three measurements were automatically saved in the URIGHT TD-3128 BP monitor. In this study, only the second and third measurements were used to find an average BP result for each patient.

\section{Data analysis}

The SPSS V22 software (university license) was used to analyze the data. Descriptive statistics, including frequency, percentage, mean, and standard deviation, were used to analyze the participants' demographics, lifestyle and management knowledge, health literacy, self-management behaviors, and BP levels. To compare the experiment and control groups, chi-squared and Fisher's exact tests were applied to the categorical factors and the independent $t$-test tested for continuous factors with normal distribution (with statistical significance at $P<0.05$ ). The Wilcoxon-Mann-Whitney test was used to test for continuous factors with abnormal distribution. Some baseline factors were different between the experiment and control groups. Therefore, multiple logistic regression was applied to compare the differences in the mean changes between the baseline and 3-month measurements (ie, BP levels, BMI, WC, lifestyle and management knowledge, health literacy, self-management behaviors, and drug and appointment adherence) of each group and between group.

\section{Ethical approval}

This study was reviewed and approved by the Institutional Review Boards of the Ethical Committee of Maharat Nakhon Ratchasima Hospital. Each participant read and signed a written informed-consent form. Code names were assigned to each participant to protect their privacy and the data was kept confidential. The control PCU would receive the integrated program after the study was completed.

\section{Results}

\section{First phase}

Four group discussions involving all stakeholders resulted in identifying the needs of and improvements to Thailand's HT care system based on the 20-item HLCM. Seven features of the HT care system were found to be appropriate. The other features were improved through the following activities: 1) established a collaborative team; 2) installed software to support HBPM; 3) provided the HT CPG to healthcare personnel so they could make better care decisions; 4) created a picture book to increase awareness, knowledge, and selfmanagement practices among HT patients; and 5) produced a 2-day workshop to increase HT self-management using a music video that encouraged self-care (see Table 1 for the workshop schedule).

\section{Second phase}

From a group of 513 patients, 63 patients with poorly controlled HT were recruited to be in the study's experimental group, and from a group of 516 patients, 65 were chosen to be in the control group (Figure 1). Of these, 62 experiment participants and 60 control participants completed the followup interview at 3 months post-intervention. The median age of the control group was 64.0 years, which was slightly higher than that of the experiment group (Table 2). Additionally, the proportion of female patients in the control group was $70 \%$, while $50 \%$ of the experiment group were female.

There were no significant differences in the baseline measurements between both groups (ie, BMI, WC, marital status, education level, number of family members, financial status, 


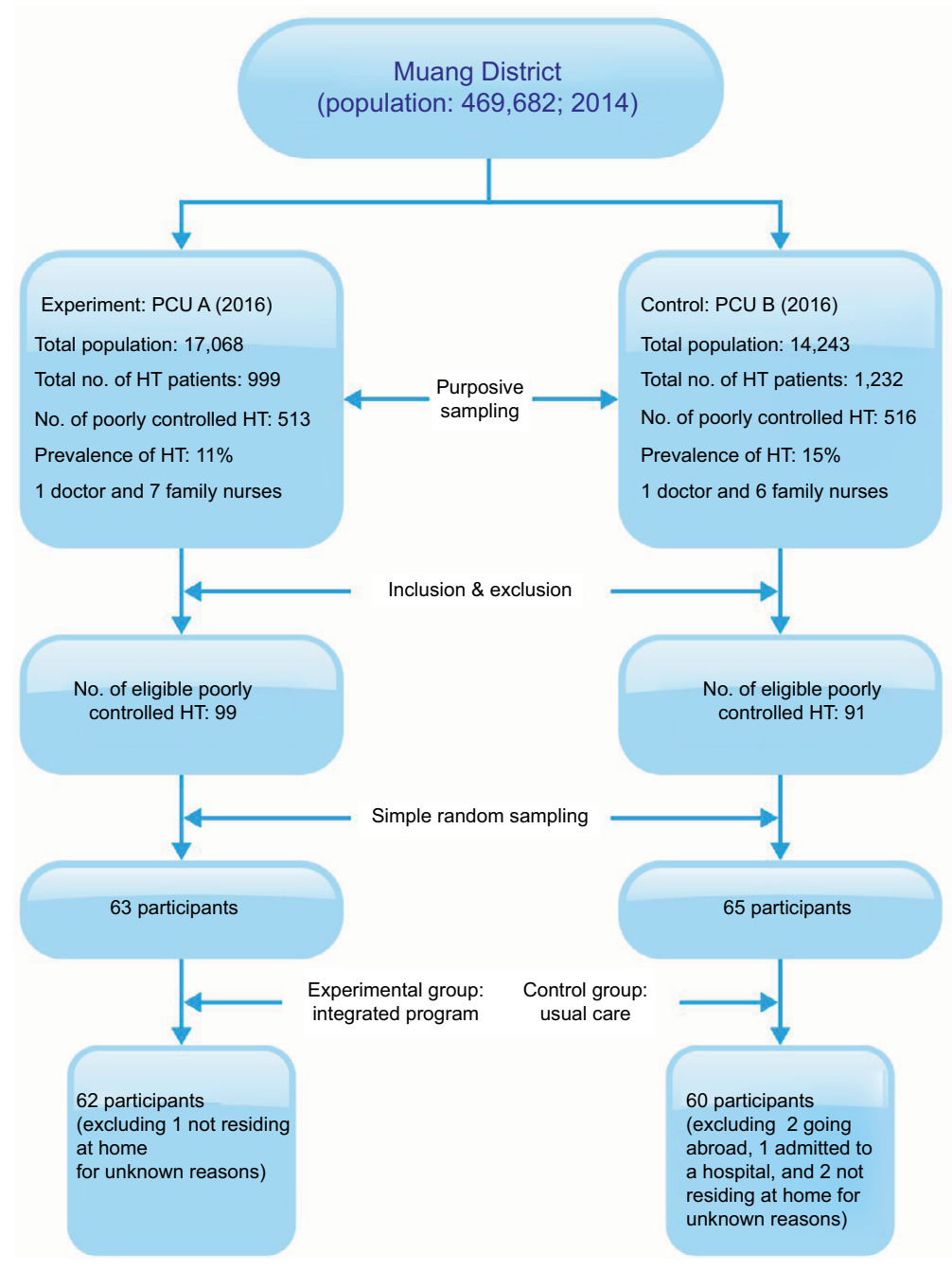

Figure I Flow diagram of the participant sampling.

Abbreviation: HT, hypertension; PCU, primary care unit.

occupation, health insurance, cigarette smoking, alcohol drinking, drug management, comorbidities, writing messages for others to understand, reading comprehension, talking to others understandably, hearing voices clearly, clear vision, daily activities, going out independently, self-observation in self-care of chronic diseases, self-management behaviors, and drug and appointment adherence). It can be concluded that the majority of both groups graduated from primary school or lower, had sufficient income, were enrolled in Thailand's Universal Coverage Scheme (health insurance), were nonsmokers and nondrinkers, and self-administered their drugs. Nearly two-thirds were married/cohabiting, employed/ self-employed, and diagnosed with the comorbidity of hyperlipidemia and diabetes mellitus. The average values for BMI and WC illustrated that participants were overweight. On average, they demonstrated fair health literacy and potential literacy, high scores in self-care of chronic diseases, adequate self-management behaviors, and medium adherence.

There were significant differences between the baseline and 3-month values for experience sharing in self-care of chronic diseases, lifestyle and management knowledge, sHBP, and dHBP. The median scores for experience sharing and lifestyle and management knowledge in the experiment group were higher than those of the control group. In the experiment group, the mean (SD) sHBP and dHBP levels at baseline were 134.7 (13.4) and 80.7 (8.2) $\mathrm{mmHg}$, respectively, while these values in the control group were 129.3 (14.0) and 75.7 (7.5) $\mathrm{mmHg}$, respectively. The average sHBP and dHBP levels were higher in the experiment group than the control group.

Table 3 presents comparison of the mean differences between the experimental group and the control group at 
Table 2 Baseline characteristics of participants with poorly controlled HT

\begin{tabular}{|c|c|c|c|}
\hline Characteristics & $\begin{array}{l}\text { Experiment } \\
(n=62) \\
\text { Number }(\%)\end{array}$ & $\begin{array}{l}\text { Control } \\
(n=60) \\
\text { Number }(\%)\end{array}$ & $P$-value \\
\hline Age, median, years & 61.5 & 64.0 & $0.043^{\mathrm{a}, \mathrm{b}}$ \\
\hline Female & $31(50.0)$ & $42(70.0)$ & $0.024^{b, c}$ \\
\hline BMI, mean (SD), kg/m² & $27.6(4.8)$ & $27.4(4.1)$ & $0.770^{d}$ \\
\hline WC, mean (SD), cm & 94.5 (II.7) & $90.68(11.0)$ & $0.069^{d}$ \\
\hline $\begin{array}{l}\text { Single, separated, divorced, } \\
\text { or widowed }\end{array}$ & $19(30.6)$ & $24(40.0)$ & $0.280^{c}$ \\
\hline Primary school or lower & $48(77.4)$ & 43 (7I.7) & $0.466^{c}$ \\
\hline Family members $\leq 4$ & $33(53.2)$ & $34(56.7)$ & $0.703^{c}$ \\
\hline $\begin{array}{l}\text { Not enough income or high } \\
\text { debt }\end{array}$ & $16(25.8)$ & $18(31.0)$ & $0.319^{c}$ \\
\hline Unemployed & $24(38.7)$ & $24(40.0)$ & $0.884^{c}$ \\
\hline Health insurance: UC & $52(83.9)$ & 55 (91.7) & $0.190^{c}$ \\
\hline Nonsmoking & $55(94.8)$ & $56(96.6)$ & $1.000^{\mathrm{e}}$ \\
\hline Nondrinking & $4 I(69.5)$ & $49(83.1)$ & $0.083^{c}$ \\
\hline \multicolumn{4}{|l|}{ Drug management } \\
\hline Self-preparation & $62(100)$ & $58(96.7)$ & $0.149^{e}$ \\
\hline Self-administration & $58(93.5)$ & $54(91.5)$ & $0.673^{\mathrm{e}}$ \\
\hline \multicolumn{4}{|l|}{ Comorbidity } \\
\hline Hyperlipidemia & $35(56.5)$ & 43 (7I.7) & $0.080^{c}$ \\
\hline Diabetes mellitus & $28(45.2)$ & $35(58.3)$ & $0.146^{c}$ \\
\hline Renal disease & $7(I I .3)$ & $7(I I .7)$ & $0.948^{c}$ \\
\hline Coronary artery disease & $2(3.2)$ & $4(6.7)$ & $0.382^{\mathrm{e}}$ \\
\hline Cerebrovascular disease & $3(4.9)$ & $\mathrm{I}(\mathrm{I} .7)$ & $0.319^{\mathrm{e}}$ \\
\hline \multicolumn{4}{|l|}{$\begin{array}{l}\text { Literacy and potential health } \\
\text { literacy scores, median (out } \\
\text { of } 4 \text { total) }\end{array}$} \\
\hline $\begin{array}{l}\text { Writing messages for } \\
\text { others to understand }\end{array}$ & 2 & 2 & $0.084^{\mathrm{a}}$ \\
\hline Reading comprehension & 3 & 2 & $0.075^{\mathrm{a}}$ \\
\hline $\begin{array}{l}\text { Talking to others } \\
\text { understandably }\end{array}$ & 3 & 3 & $0.156^{a}$ \\
\hline Hearing voices clearly & 3 & 3 & $0.709^{\mathrm{a}}$ \\
\hline Clear vision & 3 & 3 & $0.288^{\mathrm{a}}$ \\
\hline Daily activities & 3 & 3 & $0.427^{a}$ \\
\hline Going out independently & 3 & 3 & $0.756^{\mathrm{a}}$ \\
\hline \multicolumn{4}{|l|}{$\begin{array}{l}\text { Self-care of chronic diseases } \\
\text { scores, median (out of } \\
10 \text { total) }\end{array}$} \\
\hline Experience sharing & 8.5 & 7.6 & $0.019^{a, b}$ \\
\hline Self-observation & 8.1 & 7.9 & $0.254^{\mathrm{a}}$ \\
\hline $\begin{array}{l}\text { Lifestyle and management } \\
\text { knowledge scores, median } \\
\text { (out of } 10 \text { total) }\end{array}$ & 7.0 & 6.0 & $0.033^{\mathrm{a}, \mathrm{b}}$ \\
\hline $\begin{array}{l}\text { Self-management behavior } \\
\text { scores, mean (SD; out of } \\
3 \text { total) }\end{array}$ & $2.4(0.3)$ & $2.4(0.3)$ & $0.440^{d}$ \\
\hline $\begin{array}{l}\text { Drug and appointment } \\
\text { adherence scores, median, } \\
\text { (out of } 8 \text { total) }\end{array}$ & 7.5 & 7.0 & $0.4 \mathrm{II}^{\mathrm{a}}$ \\
\hline sHBP, mean (SD), mmHg & $134.7(13.4)$ & $129.3(14.0)$ & $0.030^{\mathrm{b}, \mathrm{c}}$ \\
\hline $\mathrm{dHBP}$, mean (SD), mmHg & $80.7(8.2)$ & $75.7(7.5)$ & $0.00 I^{b, c}$ \\
\hline
\end{tabular}

Notes: ${ }^{a}$ The Wilcoxon-Mann-Whitney test; ${ }^{b}$ Statistical significance; ${ }^{\circ}$ Chi-squared test; 'Independent $t$-test; 'Fisher's exact test.

Abbreviations: BMI, body mass index; $\mathrm{cm}$, centimeter; $\mathrm{dHBP}$, diastolic home blood pressure; sHBP, systolic home blood pressure; UC, Universal Coverage Scheme; WC, waist circumference. baseline and the effect of the 3-month integrated program. The differences of unadjusted mean change between baseline and 3 months of sHBP was $7.13 \mathrm{mmHg}$ while of dHBP was $4.65 \mathrm{mmHg}$. Unadjusted mean difference of 3-month BMI and $\mathrm{WC}$ decreased $0.86 \mathrm{~kg} / \mathrm{m}^{2}$ and $0.55 \mathrm{~cm}$ from baseline orderly. Unadjusted mean difference of 3-month scores of lifestyle and management knowledge, self-observation, selfmanagement behaviors, and drug and appointment adherence rose from baseline by $0.64,0.47,0.18$, and 0.25 respectively. Only 3-month mean difference score of experience sharing did not increase from baseline.

There were significant differences between the experiment and control groups regarding the mean changes in sHBP, dHBP, BMI, lifestyle and management knowledge, and self-management behaviors. At the end of 3-month follow-up, the experiment group showed mean difference (lower bound, upper bound) that their sHBP, dHBP, and BMI changed as the follows; -4.61 (95\% CI $-8.32,-0.90)$ $\mathrm{mmHg}(P$-value 0.015$),-3.5$ (95\% CI $-5.31,-1.72) \mathrm{mmHg}$ $(P$-value $<0.001)$, and $-0.86(95 \% \mathrm{CI}-1.29,-042)(P$-value $<0.001)$, respectively. Their mean difference (lower bound, upper bound) scores in lifestyle and management knowledge had increased by $0.76(95 \% \mathrm{CI} 0.15,1.38)$ points $(P=0.016)$, and self-management behaviors had increased by $0.14(95 \%$ CI $0.06,0.24)$ points $(P=0.004)$.

\section{Discussion}

The findings indicate that patients with poorly controlled HT living in an urban area of Thailand have hyperlipidemia, diabetes mellitus, low education, moderate knowledge and literacy, high self-care of chronic diseases, and medium adherence, leading to adequate self-management behaviors. Nearly half of the participants in this study scored poorly in writing messages for others to understand, reading comprehension, and nonmedical adherence. Most of the participants adhered to their appointments with their PCU.

According to these identified patterns, the tools of the integrated program were designed to be easily read, such as a picture book and lyrics to a music video. The participants who received the integrated program, HBPM tool, and VHV support achieved significantly greater improvements in HT knowledge and self-management behaviors than the control group. Moreover, the participants' sHBP, dHBP, and BMI levels were effectively reduced by this program. This could be explained by the gap in improving HT knowledge versus adherence and health literacy. Thus, this program significantly increased HT knowledge in the experimental group, compared with the control group, resulting in significant increases 
Table 3 Comparison of the integrated program's effects on the mean statistical changes between the experiment and control groups

\begin{tabular}{|c|c|c|c|c|}
\hline \multirow[t]{2}{*}{ Outcomes } & \multicolumn{2}{|l|}{ Mean (SD) } & \multirow{2}{*}{$\begin{array}{l}\text { Unadjusted mean } \\
\text { difference } \\
(95 \% \mathrm{Cl})\end{array}$} & \multirow{2}{*}{$\begin{array}{l}\text { Adjusted mean } \\
\text { difference } \\
(95 \% \mathrm{Cl})\end{array}$} \\
\hline & $\begin{array}{l}\text { Experimental } \\
\text { group }\end{array}$ & $\begin{array}{l}\text { Control } \\
\text { group }\end{array}$ & & \\
\hline \multicolumn{5}{|l|}{ sHBP } \\
\hline Baseline & I34.72 (|3.38) & I29.27 (I4.0I) & $5.45(0.54$ to 10.36$)$ & \\
\hline At 3 months & |30.2| ( 11.88$)$ & $131.89(12.31)$ & $-1.68(-6.02$ to 2.66$)$ & $-4.61(-8.32 \text { to }-0.90)^{\mathrm{a}}$ \\
\hline \multicolumn{5}{|l|}{$\mathrm{dHBP}$} \\
\hline Baseline & $80.66(8.22)$ & $75.70(7.50)$ & $4.95(2.13,7.78)$ & \\
\hline At 3 months & 77.59 (7.94) & $77.29(6.82)$ & $0.30(-2.36$ to 2.95$)$ & $-3.52(-5.3 \mid \text { to }-1.72)^{\mathrm{a}}$ \\
\hline \multicolumn{5}{|l|}{ BMI } \\
\hline Baseline & $27.65(4.84)$ & $27.4 I(4 . I I)$ & $0.24(-1.37$ to 1.85$)$ & \\
\hline At 3 months & $27.53(4.68)$ & $28.15(4.66)$ & $-0.62(-2.30$ to 1.05$)$ & $-0.86(-1.29 \text { to }-0.42)^{\mathrm{a}}$ \\
\hline \multicolumn{5}{|l|}{ WC } \\
\hline Baseline & $94.45(11.7 I)$ & $90.68(10.96)$ & $3.77(-0.30$ to 7.84$)$ & \\
\hline At 3 months & $95.56(12.01)$ & $92.35(11.61)$ & $3.22(-1.02$ to 7.45$)$ & $-1.63(-3.83$ to 0.57$)$ \\
\hline \multicolumn{5}{|c|}{ Lifestyle and management knowledge } \\
\hline Baseline & $6.34(1.97)$ & $5.68(1.86)$ & $0.66(-0.03$ to 1.34$)$ & \\
\hline At 3 months & 7.55 (1.49) & $6.25(2.01)$ & $1.30(0.67$ to 1.93$)$ & $0.76(0.15 \text { to } 1.38)^{\mathrm{a}}$ \\
\hline \multicolumn{5}{|c|}{ Health literacy of chronic disease } \\
\hline \multicolumn{5}{|c|}{ Experience sharing } \\
\hline Baseline & $8.09(1.74)$ & $7.4 I(1.78)$ & 0.69 (0.05 to I.32) & \\
\hline At 3 months & $8.45(1.53)$ & $7.87(1.56)$ & $0.59(0.03$ to 1.14$)$ & $0.26(-0.3$ I to 0.83$)$ \\
\hline \multicolumn{5}{|l|}{ Self-observation } \\
\hline Baseline & $8.11(1.52)$ & $7.88(1.37)$ & $0.23(-0.29$ to 0.75$)$ & \\
\hline At 3 months & $8.50(1.43)$ & $7.80(1.59)$ & $0.70(0.15$ to 1.24$)$ & $0.37(-0.17$ to 0.91$)$ \\
\hline \multicolumn{5}{|c|}{ Self-management behaviors } \\
\hline Baseline & $2.39(0.25)$ & $2.43(0.27)$ & $-0.04(-0.13$ to 0.06$)$ & \\
\hline At 3 months & $2.60(0.27)$ & $2.46(0.21)$ & $0.14(0.05$ to 0.22$)$ & $0.15(0.06 \text { to } 0.24)^{\mathrm{a}}$ \\
\hline \multicolumn{5}{|c|}{ Drug and appointment adherence } \\
\hline Baseline & $7.18(1.01)$ & $7.06(1.00)$ & $0.13(-0.24$ to 0.49$)$ & \\
\hline At 3 months & $7.48(0.94)$ & $7.11(1.22)$ & $0.38(-0.02$ to 0.77$)$ & $0.34(-0.03$ to 0.72$)$ \\
\hline
\end{tabular}

Notes: aStatistical significance $(P<0.05)$; the adjusted factors: age, sex, sHBP, dHBP, lifestyle and management knowledge, and self-care of chronic diseases (experience sharing).

Abbreviations: BMI, body mass index; $\mathrm{dHBP}$, diastolic home blood pressure; sHBP, systolic home blood pressure; WC, waist circumference.

in positive self-management behavior; however, there were no changes in self-care of chronic diseases and adherence score, as the mean baseline scores were already high.

In terms of the $\mathrm{sHBP} / \mathrm{dHBP}$ reductions, there were two items in the HLCM that had a significant impact: forming a team and improving medication adherence and accuracy. These items were addressed in the 2-day workshop. Two previous studies found that the multidisciplinary-team approach affected $\mathrm{sBP} / \mathrm{dBP}$ reduction in patients with poorly controlled HT. ${ }^{26,27}$ Additionally, working in a multidisciplinary team was found to increase adherence among such patients. ${ }^{26}$ Improving medication knowledge also improves medication adherence and lifestyle change, ${ }^{28,29}$ whereas low adherence to antihypertensive medication will most likely lead to poorly controlled HT and HT recidivism. ${ }^{11,30}$

The integrated program of the present study also provided and supported HBPM, which is another useful intervention in treating HT. Medication adherence was improved by HBPM, especially when combined with other adherence strategies. HBPM itself has been proven to effectively lower $\mathrm{BP}$ as well. ${ }^{14}$

This program employed another important strategy for reducing BP: self-management. Self-management supports interventions that focus on behavioral change, which is most effective in terms of improving individuals' quality of life and health outcomes. ${ }^{31}$ This program provides self-management support, which is one of the five domains of CCM and is related to 16 out of 20 items of the HCLM. ${ }^{13}$ Interventions that include home visits for HT management have also proven their effectiveness in improving all outcomes and promoting an individual's ability to self-manage their HT care. ${ }^{32}$ In the present study, the VHVs were trained using refresher courses on HT and HBP measurement and asked the participants three Thai-modified questions during their home visits or calls to support patients with poorly controlled HT in the experiment group. A hotline group was also established to allow the family-care team to communicate and support the VHVs' work in the community. 


\section{Strengths and limitations}

There were limitations in the present study. The quasiexperiment design was chosen because there may have been an increased chance of contamination if poorly controlled HT from only one PCU were randomized into an experiment and control group; however, budget limitations, especially in providing the HBP measurement tools, prevented the researchers from including more than two PCUs in the study.

Although this quasi-experiment design had imbalance of some baseline factors, the results from the multiple regression were analyzed and the factors with differences in baseline measurements between the two groups were adjusted to better compare the differences in program effects between both groups.

\section{Conclusion}

The present study examined an integrated program, which was designed over 2 months using a multidisciplinary approach with HBPM and VHV support, for treating poorlycontrolled HT in an experiment group and compared the results to a control group, which received the usual care. For primary care patients with poorly controlled HT residing in an urban community of Thailand, the integrated program resulted in greater sHBP and dHBP reduction over 3 months of the program's implementation. Further research is needed to prove which factor is most likely to cause decreases in BP and to determine the best strategy.

\section{Acknowledgments}

The authors express their sincere gratitude to Chulalongkorn University for providing the 90th Anniversary Chulalongkorn University Fund for Doctoral Scholarship and to all the participants, VHVs, and PCUs under Maharat Nakhon Ratchasima Hospital, the research site, for their cooperation.

\section{Disclosure}

The authors report no conflicts of interest in this work.

\section{References}

1. World Health Organization (WHO). A Global Brief on Hypertension Silent Killer, Global Public Health Crisis. Geneva: WHO; 2013.

2. Kotchen TA. Hypertensive vascular disease. In: Kasper DL, Hauser S, Longo D, Larry Jameson J, Loscalzo J, editor. Harrison's Principles of Internal Medicine. 19 ed. New York, NY: McGraw-Hill; 2015.

3. WHO. Global Health Estimates (GHE). Health statistics and information system 2000-2012 [cited 16/04/16]; Available from: http:/www.who. int/healthinfo/global_burden_disease/en/. Accessed April 16, 2016.

4. Andrew P. Health Literacy Around the World: Part 1 Health Literacy Efforts Outside of the United States. USA: Institute of Medicine Roundtable on Health Literacy; 2012.
5. Mayagah K, Wayne M. A working document for discussion at the 7th Global Conference on Health Promotion. Promoting Health and Development: Closing the Implementation Gap, Nairobi, Kenya, 26-30 October 2009 [cited 2014200314 ]; Available from: http://www.who.int/healthpromotion/conferences/7gchp/Track1_Inner.pdf. Accessed April 16, 2016.

6. Kickbusch I, Pelikan JM, Apfel F, Tsouros AD, World Health Organization. Regional Office for Europe. Health Literacy: The Solid Facts. Copenhagen: WHO Regional Office for Europe; 2013.

7. Nutbeam D. Health literacy as a public health goal: a challenge for contemporary health education and communication strategies into the 21st century. Health Promot Int. 2000;15(3):259-267.

8. Krishnani A, Gong R, Kahandaliyanageiii A. Hypertension in the South-East Asia Region: an overview. Regional Health Forum. 2013;17(1):7-14.

9. Alam MG, Barri YM. Systolic blood pressure is the main etiology for poorly controlled hypertension. Am J Hypertens. 2003;16:140-143.

10. Glynn LG, Murphy AW, Smith SM, Schroeder K, Fahey T. Interventions used to improve control of blood pressure in patients with hypertension. Cochrane Database SystRev. 2010;(3):CD005182.

11. McNaughton CD, Jacobson TA, Kripalani S. Low literacy is associated with uncontrolled blood pressure in primary care patients with hypertension and heart disease. Patient Educ Couns. 2014;96:165-170.

12. Willens DE, Kripalani S, Schildcrout JS, et al. Association of brief health literacy screening and blood pressure in primary care. $J$ Health Commun. 2013;18:129-142.

13. Koh HK, Brach C, Harris LM, Parchman ML. A proposed health literate care model would constitute a systems approach to improving patients' engagement in care. Health Affairs. 2013;32(2):357-367.

14. Stergiou GS, Bliziotis IA. Home blood pressure monitoring in the diagnosis and treatment of hypertension: a systematic review. Am J Hypertens. 2010;24:123-134.

15. Cooper LA, Roter DL, Carson KA, et al. A randomized trial to improve patient-centered care and hypertension control in underserved primary care patients. J Gen Intern Med. 2011;26(11):1297-1304.

16. He J, Irazola V, Mills KT, et al. Effect of a community healthworkerled multicomponent intervention on blood pressure control in lowincome patients in Argentina: a randomized clinical trial. JAMA. 2017;318(11):1016-1025.

17. Chapter 7 Health care system of Thailand. In: Prachongsai P, editor. Thai Ministry of Public Health 2012-2016. BKK: Strategy and Planning Division of MOPH; 2016:240-307.

18. Schapira M M FKE, Hayes A, Eastwood D, et.al. The development and validation of the hypertension evaluation of lifestyle and management knowledge scale. J Clin Hypertens. 2012;14(7):461-466.

19. Dhuraku Pundit Research Center. Health Literacy Survey in Sample Population for Validity Testing by Psychometric Method (Thai Language). Bangkok: Health System Research Institute (HSRI); 2013.

20. Han H-R, Lee H, Commodore-Mensah Y, Kim M. development and validation of the hypertension self-care profile: a practical tool to measure hypertension self-care. J Cardiovasc Nurs. 2014;29(3):E11-E20.

21. Jankowska-Polanska B, Uchmanowicz I, Chudiak A, Dudek K, Morisky DE, Szymanska-Chabowska A. Psychometric properties of the Polish version of the eight-item Morisky Medication Adherence Scale in hypertensive adults. Patient Prefer. Adherence. 2016;10:1759-1766.

22. Nwabuo C C DSM, Weeks K, Young J H. Factors associated with appointment non-adherence among African-Americans with severe, poorly controlled hypertension. PLoS One. 2014;9(8):1-7.

23. Eldredge LKB, Parcel GS, Kok G, Gottlieb NH, Fernández ME. Planning Health Promotion Programs: An Intervention Mapping Approach. 1st ed. USA: Jossey-Bass; 2006.

24. Bloom BS. Learning for mastery. Eval Comment. 1968;1(2):1-5.

25. Bernard R. Chapter 2 descriptive statistics. In: Rosner B, editor. Fundamental of Biostatistics Seventh Edition. 5 ed. Canada: Duxbury; 2000: 7-44.

26. Fortuna RJ, Nagel AK, Rose E, et al. Effectiveness of a multidisciplinary intervention to improve hypertension control in an urban underserved practice. J Am Soc Hypertens. 2015;9(12):966-974. 
27. O’Neill JL, Cunningham TL, Wiitala WL, Bartley EP. Collaborative hypertension case management by registered nurses and clinical pharmacy specialists within the patient aligned care teams (PACT) model. J Gen Intern Medi. 2014;29(Suppl 2):S675-S681.

28. Gwadry-Sridhar FH, Manias E, Lal L, et al. Impact of interventions on medication adherence and blood pressure control in patients with essential hypertension: a systematic review by the ISPOR medication adherence and persistence special interest group. Value Health. 2013;16:863-871.

29. Safeer RS, Cooke CE, Keenan J. The impact of health literacy on cardiovascular disease. Vasc Health Risk Manag. 2006;2(4):457-464.
30. Sandhu A, Ho M, Asche S, et al. Recidivism to uncontrolled blood pressure in patients with previously controlled hypertension. Am Heart J. 2015;169(79):1-7.

31. Doorley P, Price G. Framework for self-management support, long-term health conditions [cited 12/02/2017]; Available from: https://www.icgpeducation.ie/chronic-condition-self-management/HSE_CHRONIC_ V5SINGLE.pdf. Accessed February 12, 2017.

32. Park E, Kim JS. The impact of a nurse-led home visitation program on hypertension self-management among older community-dwelling Koreans. Public Health Nursing. 2015;33(1):42-52.
Integrated Blood Pressure Control

\section{Publish your work in this journal}

Integrated Blood Pressure Control is an international, peer-reviewed open-access journal focusing on the integrated approach to managing hypertension and risk reduction. Treating the patient and comorbidities together with diet and lifestyle modification and optimizing healthcare resources through a multidisciplinary team approach constitute key

\section{Dovepress}

features of the journal. This journal is indexed on American Chemical Society's Chemical Abstracts Service (CAS). The manuscript management system is completely online and includes a very quick and fair peerreview system, which is all easy to use. Visit http://www.dovepress.com/ testimonials.php to read real quotes from published authors.

Submit your manuscript here: https://www.dovepress.com/integrated-blood-pressure-control-journal 